\title{
Perspectives
}

\section{Renewable Energy Systems: Development and Perspectives of a Hybrid Solar-Wind System}

\author{
J.B.V. Subrahmanyam \\ EEE Dept \\ Bharat Institute of \\ Engineering \\ \&Technology \\ India \\ jbvsjnm@gmail.com
}

\author{
P. Alluvada \\ EEE Dept \\ Bharat Institute of \\ Engineering \\ \&Technology \\ India \\ allubiet@gmail.com
}

\author{
Bandana \\ Bharat Institute \\ of Engineering \& \\ Technology \\ India \\ bandana.elec@ \\ gmail.com
}

\author{
K. Bhanupriya \\ Bharat Institute of \\ Engineering \& \\ Technology \\ India \\ banukandasamy@ \\ gmail.com
}

\author{
C. Shashidhar \\ Bharat Institute of \\ Engineering \& \\ Technology \\ India \\ sasidhar84@ \\ yahoo.co.in
}

\begin{abstract}
Considering the intermittent natural energy resources and the seasonal un-balance, a phtovoltaic-wind hybrid electrical power supply system was developed to accommodate remote locations where a conventional grid connection is inconvenient or expensive. However, the hybrid system can also be applied with grid connection and owners are allowed to sell excessive power back to the electric utility. The proposed set-up consists of a photo-voltaic solar-cell array, a mast mounted wind generator, lead-acid storage batteries, an inverter unit to convert DC to $\mathrm{AC}$, electrical lighting loads, electrical heating loads, several fuse and junction boxes and associated wiring, and test instruments for measuring voltages, currents, power factors, and harmonic contamination data throughout the system. The proposed hybrid solar-wind power generating system can be extensively used to illustrate electrical concepts in hands-on laboratories and also for demonstrations in the Industrial Technology curriculum. This paper describes an analysis of local PV-wind hybrid systems for supplying electricity to a private house, farmhouse or small company with electrical power depending on the site needs. The major system components, work principle and specific working condition are presented.
\end{abstract}

Keywords- solar power; wind power; hybrid generation; renewable energy; grid

\section{INTRODUCTION}

Energy plays an important role in all types of development, including economic development. The world total energy annual consumption generally increases, with the vast majority of energy being produced by fossil fuels such as coal, oil and natural gas. In 2002 fossil fuels provided the three quarters of the total. With the current energy consumption rate, proven coal reserves should last for about 200 years, oil for approximately 40 years and natural gas for around 60 years. With constantly increasing development, diminishing fossil fuel resources and related environmental problems (e.g. emissions), sustainable development and the manner in which energy is produced and consumed is reconsidered.

Renewable energy [1], i.e., energy generated from solar, wind, biomass, geo-thermal, hydropower and ocean resources, could increase the diversity of energy supplies and offer "clean"-environmental friendly energy. Although wind and solar energy sources are significantly less productive compared to fossil fuels, the use of photovoltaic (PV) cells and wind turbines [2] has increased rapidly during the last years, especially in developed countries. Photovoltaic (PV) cells are electronic devices that are based on semiconductor technology and can produce an electric current directly from sunlight. The best silicon PV modules currently commercially available have an efficiency of over $18 \%$, and it is expected that in about 10 years' time module efficiencies may rise to $25 \%$. Wind power is basically electricity produced by a generator, which is driven by a turbine according to flowing air's aerodynamics, and is one of the fastest growing renewable energy technologies around the world.

PV modules and wind turbines [3] are now widely used in developed countries to produce electrical power in locations where it might be inconvenient or expensive to use conventional grid supplies, while other homeowners who choose the renewable energy sources prefer to connect their energy system to the grid as a huge 'battery' for some convenient grid-tied situation. However, when electricity grids are non-existent or rudimentary, all forms of energy can prove very expensive. In such cases, solar and wind energy can be highly competitive. The fact that natural energy resources are intermittent and storage batteries are expensive, has led to the utilization of so-called hybrid renewable energy systems. Any power system that incorporates two or more of the following is referred to as a hybrid power system: PV panels, wind turbines, or diesel, propane, gasoline generators. For small loads, the most common combinations [4] are PV-wind hybrid system. 
PV and wind is a good match, because inland wind speeds tend to be lower in summer, when solar energy can compensate, and higher in winter, when sunshine falls to very low levels.

In this paper, a PV-wind hybrid system is presented able to supply electricity to a private house, farm house or a small company or an apartment, with electrical power depending on the site's needs. The aim of this study is to introduce the local PV-wind hybrid system's working principle by reviewing one case where the system is connected to the grid.

\section{A. Special issues of wind turbines and PV Cells}

As both wind and solar energy sources are inconsistent and non-stable. Hybridizing solar and wind power sources together with storage batteries to cover the periods of time without sun or wind provides a stable form of power generation. However, the variable features, especially in the case of wind power, constitute a significant difference to the conventional fossil fuel, nuclear or hydro-based power generation. Even so, wind energy is currently the least expensive renewable energy technology.

Photovoltaic or PV cells, known commonly as solar cells, convert the energy from sunlight into DC electricity. PVs offer added advantages over other renewable energy sources in that they give off no noise and require insignificant maintenance. Although solar energy is well known to students (e.g. found on most calculators), their operating principles and governing relationships are unfortunately not as pedagogically simple as that of wind-turbines. However, they operate using the same semiconductor principles that govern diodes and transistors. The explanation of their functioning is straightforward and may even help many of the principles covered in semiconductor electronic classes to become more intuitive.

Wind-turbines and PV cells provide DC but most industrial uses of electricity require AC power. A semiconductor-based device known as a power inverter is used to convert the DC to AC. This device has a relatively simple operation and is a vivid illustration of many topics traditionally covered in power electronics classes.

\section{SYSTEM ANALYSIS}

\section{A. Specific site conditions for $P V$-wind hybrid system}

Intermittent and seasonally unbalanced natural energy resources are the most important reason to install a hybrid energy system. The PV-wind hybrid system suits to conditions where sun light and wind has seasonal shifts i.e., in summer the daytime is long and sun light is strong enough, while in winter the days are shorter and there are more clouds, but there is usually an increased wind resource that can complement the solar resource.

The PV-wind hybrid systems especially suit remote locations, where it is inconvenient or expensive to use conventional grid supplies. For the PV array, a direction without any obstacles facing the sun is needed. For the wind turbine, appropriate wind speed and wind direction are the key elements. The turbine should be subjected to non-turbulent wind and mounted higher than trees and other obstacles.

\section{B. System Components}

In general, a local cost-efficient, safe, and durable PV-wind hybrid system is composed of the core part (PV modules and wind turbine), the PV modules mounting, the wind turbine tower, the DC-AC inverter, the safety equipment such as fuses, connectors and lighting arrestors, the measuring instruments, the batteries, the charge controller/regulator, the backup power resource for battery storage systems, the connection wires, switches and sockets.

PV Modules can be wired together to form a PV array. By wiring modules in series the available voltage is increased and by wiring in parallel, the available current is increased. Either way, the power produced is the same. A typical PV module has a size of about 0.5 square meters (about 1.5 by 3.5 feet) and produces about 75 watts of DC electricity in full sun.

Wind turbine works the opposite of a fan. Instead of using electricity to create wind, wind turbines use wind to create electricity. Most turbines have either two or three blades. These three-bladed wind turbines are operated "upwind," with the blades facing the wind. The other common wind turbine type is the two-bladed, downwind turbine. The wind turns the blades, which spin a shaft, which is connected to a generator and produces electricity. Utility-scale turbines range in size from 50 to 750 kilowatts. Single small turbines, below 50 kilowatts, are used for homes, telecommunications dishes, or water pumping.

DC-AC inverter changes low voltage direct current (DC) power, which is produced by the PV or wind turbine or is stored in the battery, to standard AC which is most commonly 120 or 240 VAC, 50 or 60 hertz. The "modern sine wave" inverters supply uninterruptible power, i.e. there are no blackouts or brownouts. Such inverters come in sizes from 250 watts to over 8,000 watts. There are also the "modified sine wave" inverters which are cheaper and can handle most household tasks. However, this type of inverters may create a buzz in some electronic equipment and telephones, which can be an annoyance. It should be noted that inverters have made great strides in performance and price in recent years. Inverters can also provide a utility inter-tie between the renewable energy system and the utility grid, allowing the selling of excess energy to the utility. Many inverters also have built-in battery chargers to keep the batteries topped off from either the grid or your generator.

The PV modules mounting can be a ground mount that works either on rooftops or the ground, or pole mount for getting them up in the air. Both are angle-adjustable so that PV array will face the sun as near to perpendicular as possible. Many owners will adjust their mounting racks two to four times a year to get maximum exposure as the sun changes its angle during seasons. If the rooftop has a good angle to the sun, the modules could be mounted solidly to the roof without an adjustable rack. Trackers are another PV mounting option, which are pole mounts that automatically adjust themselves so that the PV faces the sun throughout the day. Because the wind turbine should be mounded into non-turbulent wind, a tall enough wind turbine tower is needed $(9 \mathrm{~m}$ above anything within $120 \mathrm{~m}$ ). And there should also be enough space to properly anchor the guy wires. 
Safety equipment includes over-current and lightning protection components. Over-current protection components such as fuses and fused disconnectors protect the system's wiring and components in the event of short circuits. Fusing protects from over-current situations, and disconnectors allow safe shutdown of system components for maintenance and repair. Fuses and fused disconnectors are rated by the amount of current they can handle. They may be as small as a few amperes, in case of measuring instruments, to as large as 400 amperes, in case of the inverter. Many renewable energy systems are in areas where thunderstorms and lightning are common. It should be considered that the wind turbine is always the highest building in the remote area. Commercial lightning arrestors can be employed to boost protection of the system's electronics against lightning.

Measuring instruments can keep track of the battery voltage, the amount of consumed power, the state of battery charge and the electricity traffic between the grid and the renewable energy system, if connected. Some instruments have more than one channel to monitor two battery banks or a battery bank and a generating source for the hybrid systems. Batteries store electrical energy produced by the renewable energy source in a reversible chemical reaction. Most renewable energy systems use lead-acid batteries, typically encased in plastic, wired together in series and parallel strings. Battery capacity is rated in amp-hours, with 1 amp-hour is the equivalent of drawing $1 \mathrm{amp}$ steadily for one hour. A typical 12-volt system may have 800 amp-hours of battery capacity. This is the equivalent of 1,200 watts for eight hours if fully discharged and starting from a fully charged state. There are many brands and types of batteries available for renewable energy systems and the two most common batteries are the L16 and golf cart sizes.

Charge controller/regulator prevents the PV array and wind turbine from over-charging the battery. Most modern controllers maintain system voltage regulation electronically by varying the width of DC pulses they send to the batteries (this is called pulse width modulation or PWM). This means the wider the pulse, the more power goes to the batteries. Another category is the "shunt type" controllers which divert excess energy into a "shunt load." Such controllers are more commonly used in wind or hydro systems, since these systems generally should not be run open circuit. Unlike a PV module, most wind and hydro turbines cannot be switched on and off by the controller. A new generation of PV controllers employs "maximum power point tracking." They take advantage of the maximum power available in the module by adjusting both current and voltage.

Backup power resource can come either from a generator or from the utility grid when too much energy is consumed or when there has not been enough renewable energy coming into the system. However, in case of the hybrid system, the latter situation may be avoided, whereas a suitable energy consuming style might assist to solve the former problem.

\section{PROCESS OF ESTABLISHING THE SYSTEM}

The process of establishing the energy supply system (Figure 1) is an extremely important step. Regardless the nature of the installed system, the calculation of the desired load and the site's resources ought to be the first step. Load analysis lists and adds up all energy consumed by the appliances powered by the system. Resource measurement affects the system structure, efficiency, and cost. The design and installation of the system requires both knowledge and experience.

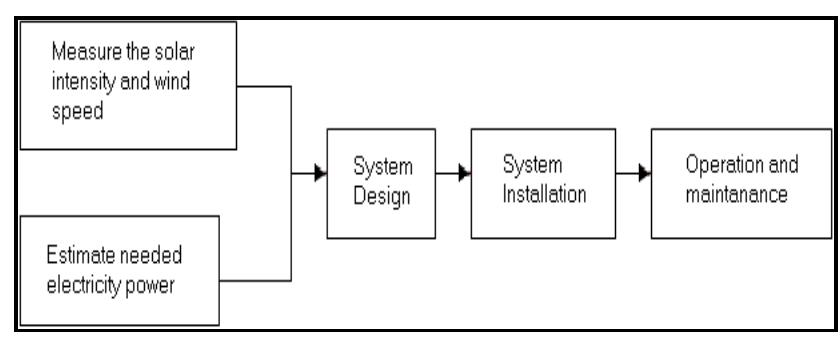

Fig. 1. Steps for establishing a hybrid solar \& wind plant

\section{A. Methodology}

In order to address the shortcomings of existing instructional techniques for electrical power systems, the system is designed and implemented with the following goals:

- To be completely different from systems traditionally employed in electricity labs (in other words, to be fresh and interesting).

- To be intimately related to real world industrial power issues such as power quality.

- To show a complex, interrelated system that is closer to the "real world" than the usual simple systems employed in educational labs.

\section{B. Establishment of a Wind/PV Hybrid Unit}

The hybrid unit contains two complete generating plants, a PV solar cell plant and a wind-turbine system. These sources are connected in parallel to a $120 \mathrm{~V}$ AC line. The PV panel output is connected to a DC/AC inverter and is then supplied from the inverter's output to a single-phase, 120 VAC load. The overall project structure is presented in Figure 2. The DC voltage measured across each PV unit (12 V DC) is shown in Figure 3. The wind turbine is installed at the top of a steel tower that has a height of 18.3 meters and a diameter of $8.9 \mathrm{~cm}$. The instrumentation panel depicted monitors the outputs of the generator using digital panel meters. One of the low maintenance features is the turbine's brush-less alternator and an internal governor. The turbine's blades are made of a carbon fiber reinforced composite that will intentionally deform as the turbine reaches its rated output. This deformation effect, changes the shape of the blade, causing it to go into a stall mode, thus limiting the rotation speed of the alternator and preventing damage in high kinds. Another feature of the wind turbine is a sophisticated internal regulator that periodically checks the line voltage and corrects in case of low voltage conditions. 


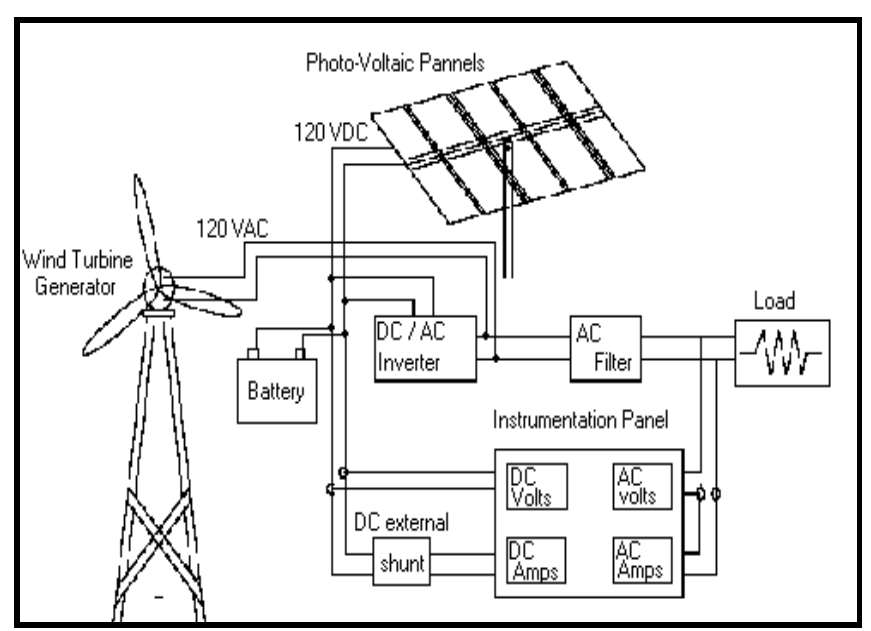

Fig. 2. A simple hybrid solar \& wind system

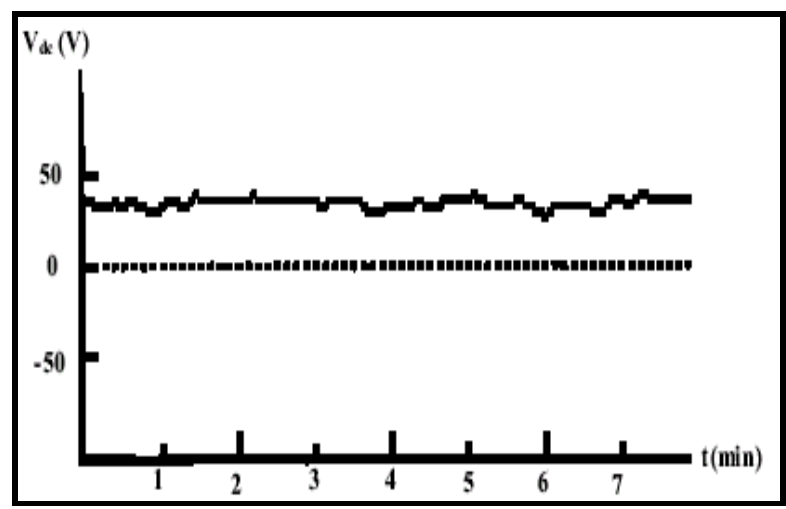

Fig. 3. The DC voltage measured across each PV unit (12 V DC)

One of the largest problems in systems containing power inverters is power quality. This problem becomes serious if the inverter used in the system does not have a good sinusoidal waveform output and causes problems such as harmonic contamination and poor voltage regulation. According to IEEE standards, a maximum of 3 to $4 \%$ total harmonic distortion may be allowed from inverter outputs. However, many inverter outputs have much larger harmonic distortion than allowed.

To monitor and store the voltage, current, power, and harmonic contamination data, two power quality analyzers (types 39 and 41) are used in this system. In addition, permanently mounted $\mathrm{AC} / \mathrm{DC}$ digital panel monitors form part of the system's instrumentation. A laptop computer is interfaced to the system via the power quality analyzers to store data in real-time. Voltage sags may cause a crucial damage to high precision measurement and protection devices, especially computer equipment present in many highly automated industrial plants. The AC filter is a circuit made up of a resistor (R), inductor (L), and a capacitor (C). Such filters are commonly installed in industrial situations to remedy power quality problems. The inverter is of a six-pulse type and the inverter and the control circuit models are both standard models in the PSCAD/EMTDC software package.

\section{FUTURE STUDY}

Figure 4 illustrates the future direction of this project. A computer measurement and control bus will be added to the system. Computer controlled relays will be added to allow all the major elements of the system to be switched in and out of the system through computer programs. The measurement bus will be connected to all the major signals in the system and will allow simultaneous data acquisition of all the major signals in the system. These improvements will allow the study of more complex issues such as power faults caused by sudden over voltages like lightning. These improvements will also provide similar benefits to electricity and electronics classes and will allow the course to be extended to control and instrumentation classes.

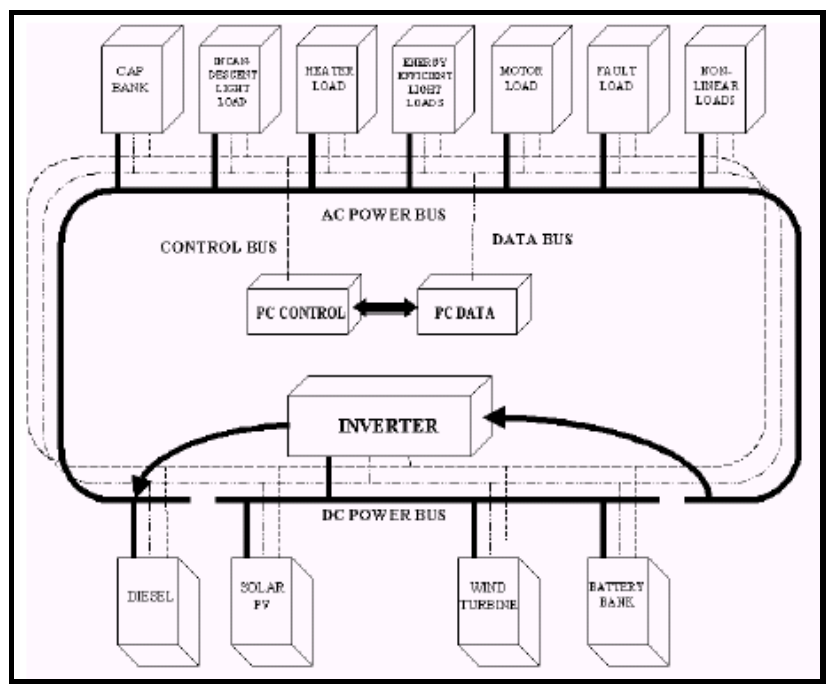

Fig. 4. Block diagram of scope for future research

\section{CONCLUSIONS}

The key element of the concept presented in this paper is that two or more renewable power sources can be connected to a power grid with complex electrical interactions. A complete hybrid power system such as the one described, may be too expensive and too labor intensive for many Industrial Technology Departments. However, many of the mentioned benefits could be gleaned from having some subset of the system, for example a PV panel, batteries, and an inverter, or even just a PV panel and a DC motor. The enhancements to instruction, especially in making electrical power measurements more physical, intuitive, and real-world-like are substantial and the costs and labor involved in some adaptation of the ideas in this paper to a smaller scale setup are reasonable.

The use of solar and wind hybrid power generation is an especially vivid and relevant choice for students of electrical technology as these are power sources of growing 
technological, political, and economic importance. Hybrid combinations of wind power, solar power, geothermal power, hydroelectric power, tidal power, biomass generated power, power from incineration of solid wastes, and many other technologies could also be considered depending on local interests and resources.

\section{REFERENCES}

[1] G. Boyle, Renewable energy: Power for a sustainable future, Oxford University Press, 2004

[2] Y. Dayu, Local photovoltaic PV wind hybrid systems with battery storage or grid connection, Master's Programme in Renewable Energy
Technology (Physics), EEE Dept., Bharat Institute of Engineering \&Technology, Hyderabad,India, 2004

[3] G. Pepermans, J. Driesen, D. Haeseldonckx, R. Belmans, W. D'haeseleer, "Distributed generation: definition, benefits and issues", Energy Policy, Vol. 33, No. 6, pp. 787-798, 2005

[4] A. M. Azmy, I. Erlich, "Impact of distributed generation on the stability of electrical power systems", IEEE Power Engineering Society General Meeting, Vol. 2, pp. $1056-1063,2005$ 